\title{
Минеральные ассоциации золото-медно-сульфидных кварц- карбонатных жил в габбро-долеритах месторождения строительного камня Чевжавара (Южная Карелия)
}

Лавров О.Б., Кулешевич Л.В.

Институт геологии КарНЦ РАН, Петрозаводск, petrlavrov@list.ru; kuleshev@krc.karelia.ru

Аннотация. Золото-медно-сульфидное оруденение в габбродолеритах месторождения строительного камня Чевжавара приурочено к кварц-карбонатным жилам, секущим пологозалегающие породы силла. Оруденение представлено несколькими минеральными типами: 1 - магнетит-пиритовым, 2 - пиритхалькопиритовым и 3 - гематит-халькозиновым. В краевых частях пирит-халькопирит-кварц-карбонатных жил развивается скарнирование: образуются зональные гранаты гроссуляр-андрадитового ряда, кальцит, эпидот, реже амфибол, кварц. Рудная минерализация продуктивных золото-медно-сульфидных жил 2 типа представлена пиритом, халькопиритом, борнитом, Se-борнитом, Se-галенитом, клаусталитом, золотом, баритом. Содержание золота достигает 8-31 г/т. Жилы 3 типа содержат гематит, халькозин, халцедон, кварц, в них встречается тонкодисперсное золото. Рудные минералы прорастают стильпномеланом. Локально развиты жилы кальцита и амфибол-асбеста. Типоморфными элементами рудной минерализации являются $\mathrm{Cu}, \mathrm{Au}, \mathrm{Co}$, $\mathrm{Se}, \mathrm{Zn}, \mathrm{Fe}$ (в окисленной форме).

Ключевые слова: сульфиды меди, золото, клаусталит, палеопротерозой габбродолериты, метасоматиты, Карелия.

\section{Mineral associations of gold-copper-sulphide quartz-carbonate veins in gabbro-dolerites from the Chavzhavara building stone deposit, Southern Karelia}

\author{
Lavrov O.B., Kuleshevich L.V. \\ Institute of Geology, KarRC RAS, Petrozavodsk, petrlavrov@list.ru; kuleshev@krc.karelia.ru
}

\begin{abstract}
Gold-copper suphide mineralization in the gabbro-dolerites of the Chevzhavara building stone deposit is confined to quartz-carbonate veins cutting the gently dipping rocks of the sill. The mineralization consists of several mineral types: 1 - magnetite-pyrite, 2 - pyrite-chalcopyrite, and 3 - hematite-chalcosine. Skarn formation evolves on the margins of pyrite-chalcopyrite-quartz-carbonate veins, so that zonal grossular-andradite series garnet, calcite, epidote and lesser amphibole and quartz are formed. The ore mineralization of productive gold-copper-sulphide veins of type 2 is represented by pyrite, chalcopyrite, bornite, Se-bornite, Se-galena, clausthalite, gold and barite. Gold concentration is up to 8-31 g/t. Veins of type 3 contain hematite, chalcosine, chalcedony and quartz;finely dispersed gold is occasionally encountered. The ore minerals are intergrown by stilpnomelane. Calcite and amphibole-asbestos veins occur locally. $\mathrm{Cu}, \mathrm{Au}, \mathrm{Co}, \mathrm{Se}, \mathrm{Zn}$ and $\mathrm{Fe}$ (in oxidized form) are the typomorphic elements of ore mineralization. Karelia.

Keywords: copper sulphides, gold, clausthalite, Paleoproterozoic, gabbro-dolerites, metasomatic rocks,
\end{abstract}

\section{Введение}

Месторождение строительного камня Чевжавара разрабатывается ПАО «Прионежская горная компания». Габбро-долериты образуют пологозалегающий силл $\left(\mathrm{PR}_{1} \mathrm{ld}\right)$, внедрившийся в карбонатную толщу туломозерской свиты $\left(\mathrm{PR}_{1} \mathrm{jt}\right)$. В западном борту разрабатываемого карьера зафиксированы деформации и встречаются разнообразные жилы, секущие силл. Они приурочены к системе трещин с ведущими направлениями простирания ССВ и ЗСЗ. Среди них встречаются как рудные - медно-сульфидные, так и безрудные жилы (рис. 1).

\section{Методы исследования}

Минеральный состав рудных и нерудных ассоциаций прожилков и метасоматитов изучался с использованием электронного сканирующего микроскопа VEGA II LSH (Tescan) с энергодисперсионным микроанализатором INCA Energy-350 (ИГ КарНЦ РАН). Микрокомпонентный состав руд 
и измененных пород определялся методами количественного химического или ICP-MS-анализов в аналитическом центре ИГ КарНЦ РАН (г. Петрозаводск).

\section{Результаты исследования}

Жиль 1 muпа (рис. 1) содержат крупнокристаллический пирит и магнетит. Нерудная ассоциация жил представлена кальцитом и эпидотом. В зальбандах жил по раздробленным и измененным породам развивается эпидот и хлорит. Кристаллы хорошо ограненного кубического пирита размером 1-3 см выделяются в центральной части жил на контакте с белым крупнокристаллическим кальцитом. В зальбандах жил на границе с вмещающей породой образуется магнетит, встречается хлорит.

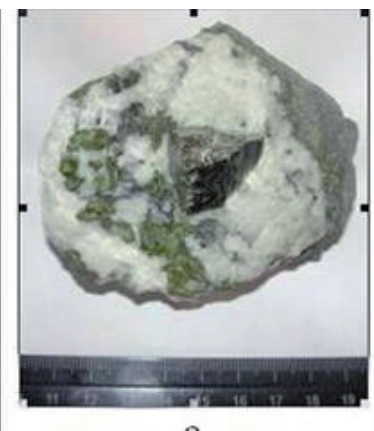

a

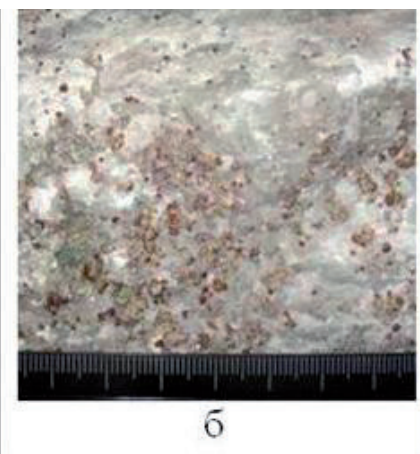

6

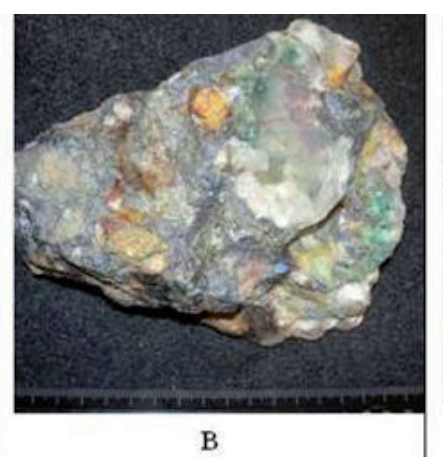

B

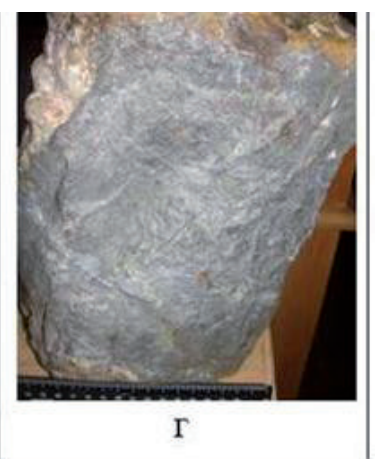

I

Рис. 1. Сульфидные жилы участка Чевжавара.

a - пирит в эпидот-кальцитовой жиле 1 типа, б - гранат-кальцитовый скарн (жилы 2 типа), в - халькопиритборнитовая руда (жилы 2 типа), г - гематит-халькозиновая руда (жилы 3 типа). Образцы из коллекции музея геологии докембрия ИГ КарНЦ РАН.

Fig. 1. Sulphide veins of the Chevzhavara prospect.

Жиль 2 типа медносульфидные (рис. 1 в). Они представлены халькопиритом, пиритом, борнитом, кальцитом, эпидотом, кварцем. В краевых частях наиболее крупных сульфидно-кварцкарбонатных жил развивается скарнирование (рис. 1 б, 2).

Минеральная ассоциация скарнов (рис. 1 б, 2) представлена кальцитом, гранатом, эпидотом, реже встречается доломит. Гранат зональный: в центре - Ca-Fe-Al (гроссуляр-андрадит), в кайме существенно $\mathrm{Fe}-\mathrm{Ca}$ (андрадит) (рис. 2, a-e). Он часто содержит включения и выглядит как «нафаршированный» (рис. 2, в-г). Нерудные минералы могли быть так называемыми «затравками». Мелкозернистая рудная вкрапленность в скарновых ассоциациях жил представлена пиритом (5-20 \%), реже встречаются халькопирит, сфалерит, галенит и более крупные гнездовые выделения барита. Метакристаллы пирита содержат включения граната и кальцита. Галенит и кварц (рис. 2 е) образуются позднее совместно с кварцем и секут скарны.

Рудная ассоциация богатых сульфидных жил (рис. 1 в, рис. 3), секущих скарны, представлена преимущественно халькопиритом, пиритом, борнитом. Кристаллы пирита кубического габитуса, цементируются халькопиритом, содержат повышенные концентрации Со. По микротрещинкам в пирит проникают мелкозернистые примеси.

К микротрещинкам в нем приурочено тонкозернистое золото (рис. 3, б-г). Состав золота (Au 83.53-44.73 \%) меняется от серебристого (Ag 16.47-27.08 \%) до электрума (Ag от 30.0-34.81 до $47.12 \%)$ по содержанию серебра.

Халькопирит с краев и по микротрещинкам замещается борнитом-1 $\left(\mathrm{Cu}_{5} \mathrm{FeS}_{4}\right)$. В более крупных зернах борнита-1 по кристаллографическим направлениям выделяются пластинчатые включения халькопирита (рис. 3, д-ж). Это свидетельствует о метастабильном состоянии борнита, избытке железа в его составе и распаде с выделением пластинок халькопирита. Распад происходит при снижающейся температуры от 300 до $170^{\circ} \mathrm{C}$ (Т устойчивости). По борниту незначительно развивается халькозин. 

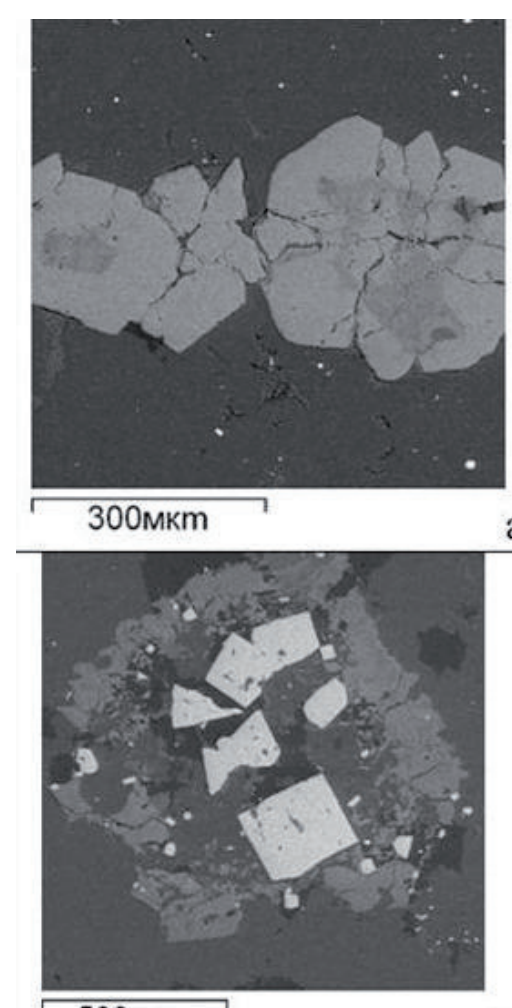

$500 \mathrm{MKm}$ a

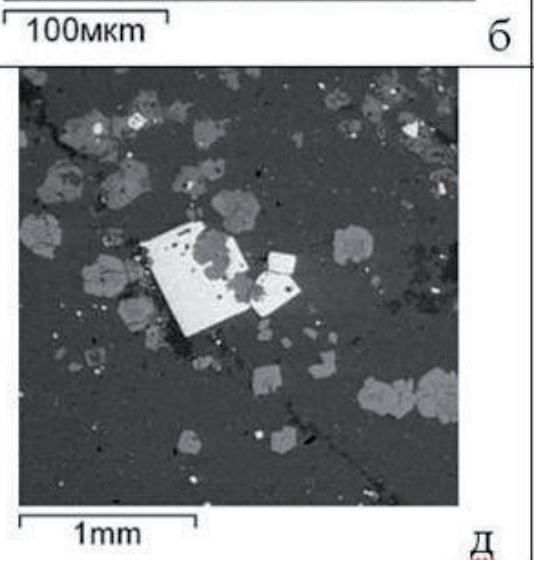

6
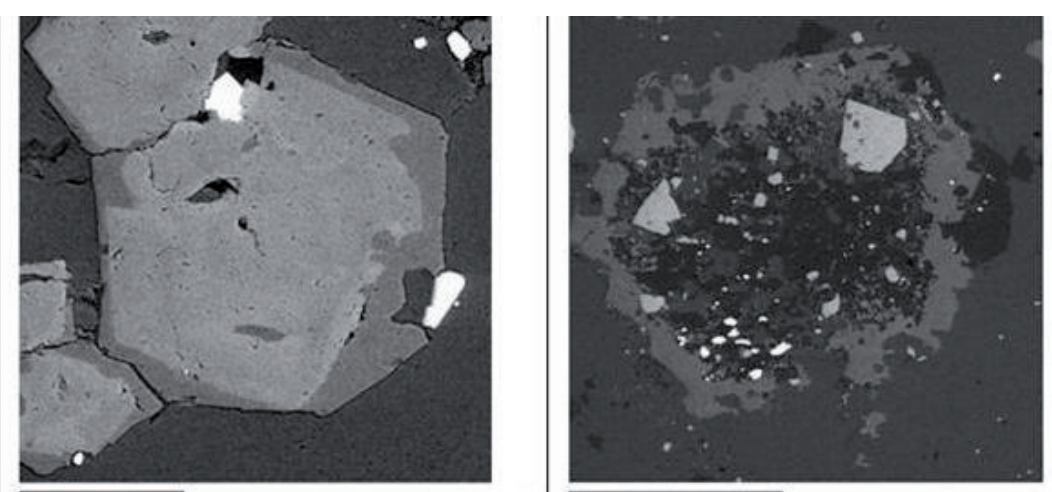

$700 \mathrm{MKm}$

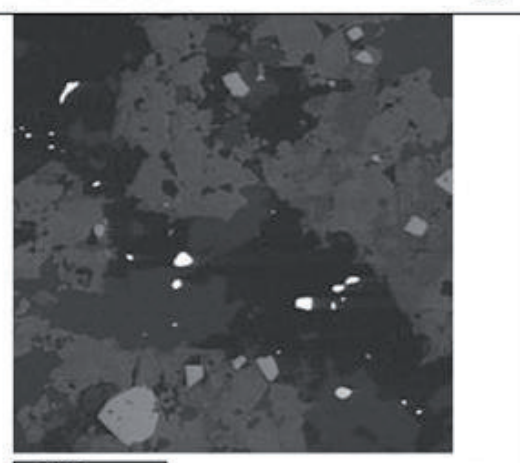

$200 \mathrm{Mkm}$

e

Рис. 2. Ассоциация жильных скарнов.

а-б - зональные гранаты, в-г - гранат с включениями кальцита, кварца, эпидота и сульфидов, д - метакристаллы пирита (белый) с включениями граната, е - тонкие кварцевые прожилки кварца (черный) с галенитом (белый), секущие гранат и кальцит.

Fig. 2. Veined skarn association.

Более «светлый борнит» представлен селенсодержащей разновидностью (рис. 3, ж-и). Растворимость селена в нем достигает 4-5 \%, а избыток селена выпадает в форме мельчайших включений селенидов и более крупных зерен в кайме и гнездах. Состава, так называемого устойчивого эскеборнита $\left(\mathrm{CuFeSe}_{2}\right)$, очевидно, достигнуто не было. По-сути, сейчас мы наблюдаем распад эвтектики с образованием мельчайших «червеобразных и каплевидных» выделений клаусталита (рис. 3, 3-и).

В галените, образующим самостоятельные мелкие зерна в ассоциации с обособленными и более крупными зернами клаусталита, содержится до 2.6-7.3 \% Se. Его можно отнести к селеногалениту. В ассоциации с галенитом иногда встречается маложелезистый светло-коричневый сфалерит (Fе до 2.6-4.93\%).

Содержание рудогенных элементов в пирит-борнит-халькопиритовых жилах составляет $\mathrm{Cu}$ 5-22.3 \%, в г/т: Ni 60, Co 180, Zn 108-418, Se 50-148, Pb 44-83, Ag 1-3, Au 0,06-1,06 (по данным ICP-MS). По данным пробирного анализа установлено 8-31 г/т Аu (выполнено в АО «Иргиредмет»).

Рудная минерализация сечется тонкими прожилками с пластинками стильпномелана.

Pydb третьего типа представлены богатыми гнездами и жилами халькозина в ассоциации с гематитом и гетитом (рис. 4). Эти жилы и гнезда образуются на более поздней низкотемпературной стадии после основных сульфидов. При отношении меди и серы в халькозине как 66:36 (дигенит) -62.6:37.4 (анилит) - 65.84:34.16 (джарлеит) его можно отнести в среднем к дигениту $\mathrm{Cu}_{1,8} \mathrm{~S}, \mathrm{c}$ верхней температурой устойчивости $\sim 83^{\circ} \mathrm{C}$. В этих богатых прожилково-гнездовых рудах иногда встречаются тонкодисперсные селениды и гораздо реже тонкодисперсное золото. Своеобразное секреционное зарастание неоднородных гнездово-жильных полостей (рис. 4, а-б) происходит от краевой части к центру с чередованием зон: сначала тонкодисперсного халцедона, проросшего гематитом, затем гематита и в центре халькозина. Морфологически образования выглядят в виде «трубочек». Поздний игольчатый гетит сечет халькозин (рис. 4 в). 
Hepудные жильц представлены крупнокристаллическим кальцитом в срастании с амфиболасбестом, либо исключительно амфибол-асбестом.

\section{Обсуждение и выводы}

Золотосодержащие медно-сульфидные жилы прослеживаются во всех палеопротерозойских структурах Карелии, иногда образуя небольшие месторождения или проявления меди и золота, такие как Воицкое, Шуезерское, Ондозерское, Муезерское, Кеч, Кончезерская группа и другие (Кулешевич и др., 2010; Кулешевич, Лавров и др. 2009; Кулешевич, Лавров, 2010; 2012). На проявлении Чевжавара золото приурочено к пирит-халькопирит-борнитовым жилам, содержащим Se-галенит и клаусталит. Золото тяготеет к микротрещинкам в пирите и относится к серебристому золоту и электруму. Сульфидной минерализации предшествовало образование жильных скарновых (андрадит-
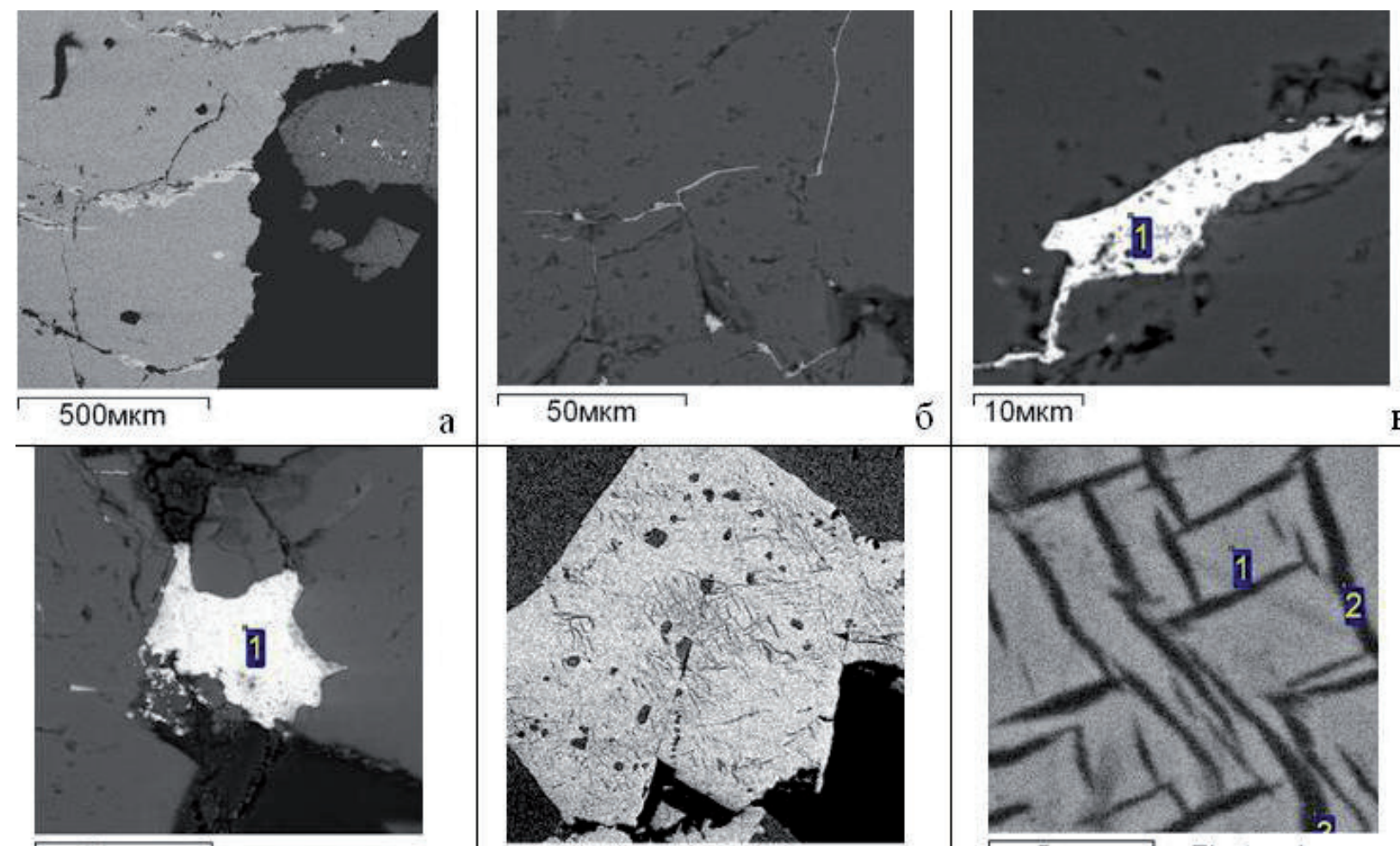

б
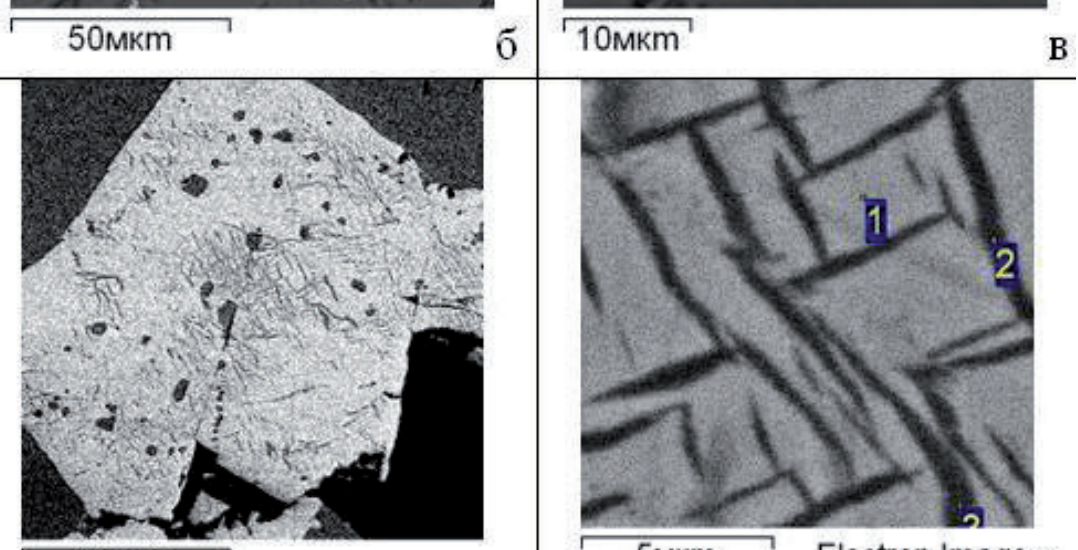

$\Gamma$
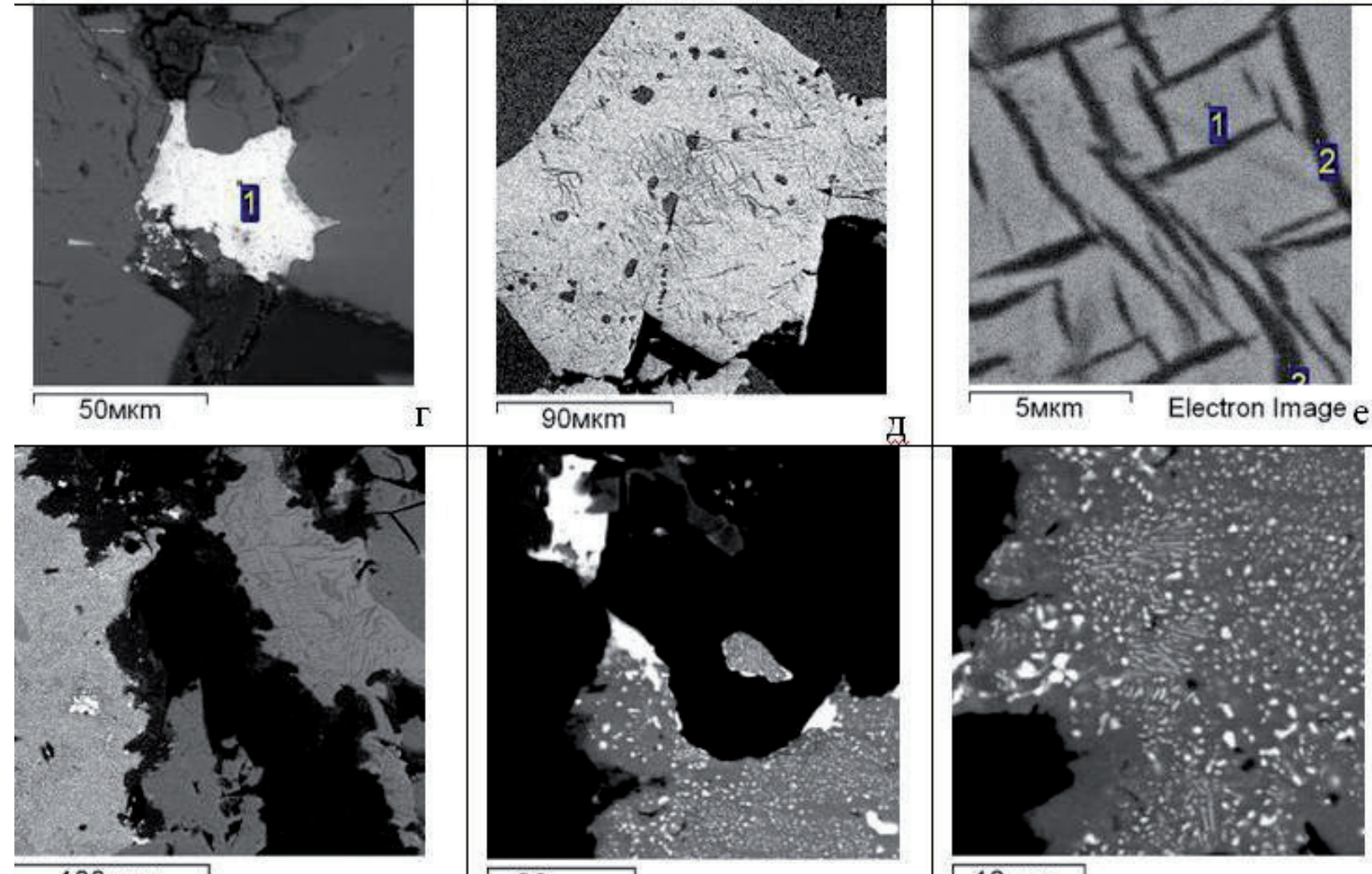

ж

$20 \mathrm{Mkm}$

3

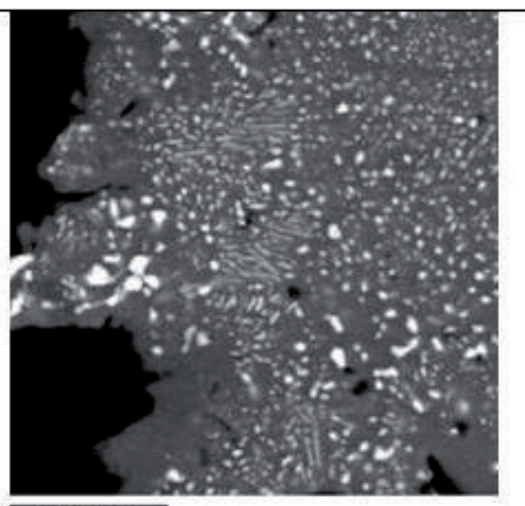

$10 \mathrm{MKm}$

Рис. 3. Халькопирит, борнит, селениды и золото в пирит-халькопиритовых рудах.

a - халькопирит замещается борнитом, пирит с галенитом (темно-серый с белыми точками, справа); б, в, г - золото в пирите; д, е - борнит с пластинками халькопирита; ж - соотношения халькопирита, борнита- 1 и борнита-2 с клаусталитом (белый); з, и - распад борнита-1 с выделением клаусталита (белый).

Fig. 3. Chalcopyrite, bornite, selenides, and gold in pyrite-chalcopyrite ores. 


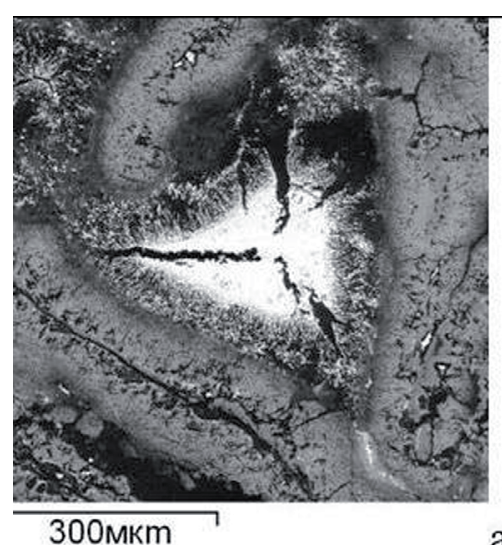

a
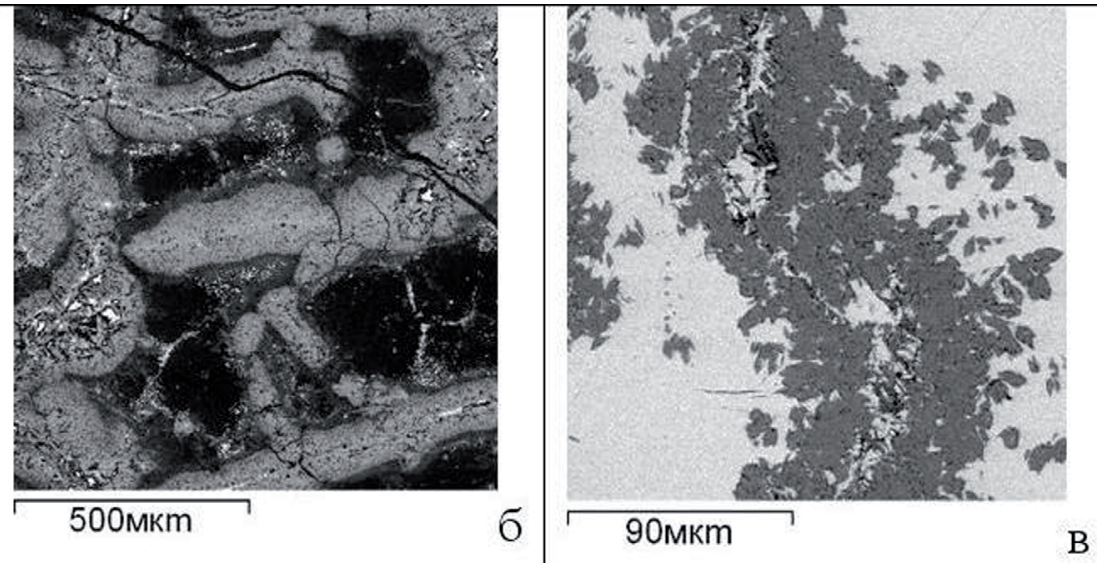

Рис. 4. Гематит-халькозиновые жилы.

a - халькозин (белый), гематит (серый); б - гематит, халцедон; в - прорастание халькозина (светлый) гетитом (темно-серый).

Fig. 4. Hematite-chalcosine veins.

кальцитовых ассоциаций). Наличие гранат-кальцитовых жильных скарнов, магнетит-пиритовых, борнит-пирит-халькопиритовых, гематит-халькозиновых рудных ассоциаций, распад селенсодержащего борнита и соотношение $\mathrm{Cu}: \mathrm{S}$ в халькозине, позволяет говорить о достаточно широком температурном интервале образования жил, снижающемся от условий скарнирования до $\sim 83-70{ }^{\circ} \mathrm{C}$.

Работа выполнена в рамках темы НИР № АААА-А18-118020290084-7.

\section{Литература}

1. Кулешевич Л.В., Голубев А.И., Лавров О.Б. Палеопротерозойские золотосодержащие медные месторождения и проявления Карельского кратона // ДАН. Т. 432. № 3. 2010. С. 376-380.

2. Кулешевич Л.В., Лавров О.Б., Голубев А.И. Золотосодержащее медносульфидное месторождение Воронов Бор и перспективы медносульфидных проявлений Карелии // Геология и полезные ископаемые Карелии. Вып. 9. 2009. С. 26-47.

3. Кулешевич Л.В., Лавров О.Б. Рудник Воицкий-Au-Cu-S-кварцевое месторождение в Северо-Выгозерской палеопротерозойской структуре Карелии // Полезные ископаемые Карелии. 2010. С. 116-130.

4. Кулешевич Л.В., Лавров О.Б. История открытия и минералогия Воицкого рудника (Карелия) // Записки РМО. № 5. 2012. С. 59-67. 